\title{
Difference of Foot Posture in Two Cases of Exercise-Induced Foot Dystonia
}

\author{
Abdul Qayyum Rana Bilun Naz Boke \\ Parkinson's Clinic of Eastern Toronto and Movement Disorders Centre, Toronto, Ont., Canada
}

Dear Sir,

Limb dystonias are characterized by involuntary abnormal twisting, curling or other patterned movements and postural abnormalities of the involved limb. When this abnormal movement is linked to a specific task, the condition is called a taskspecific dystonia of that limb [1]. Symptoms of dystonia appear to be action induced in the majority of reported cases [2]. Adult-onset focal dystonias usually involve learned, automated types of movements like writing and playing musical instruments. Drug-induced dystonias, Parkinson's disease, levodopa treatmentinduced dyskinesias and psychogenic conditions are among the most common causes considered in the differential diagnosis [3]. Nerve conduction studies as well as EMG are useful to rule out peripheral nerves or muscle conditions. Structural imaging methods such as CT scan or MRI of the brain also prove to be useful in ruling out pathology involving the basal ganglia or other parts of brain before a final diagnosis is made. Botulinum toxin is considered to be the preferred mode of therapy for task-specific dystonias [4], whereas levodopa is considered the most effective treatment for dopa-responsive dystonia [5]. Anticholinergic drugs, anticonvulsants, benzodiazepines and baclofen are considered as alternative treatment options, but the main limiting factor to these drugs is a wide range of potential side effects.
In most foot dystonias, the foot is usually plantar flexed and inverted [2]. However, the two cases of action-induced foot dystonia we present involve one patient who's foot was plantar flexed with downward curling of toes, whereas the other patient's foot was dorsiflexed and everted. Difference in foot posture in these two cases not only indicates diversity of abnormal postures which is not uncommon even in dystonia of other body parts but also highlights the complexity of neural mechanisms involved in dystonia. If a patient were to get treatment with botulinum toxin, careful assessment of abnormal posture of affected body parts becomes a very important factor in deciding which muscles should be injected.

\section{Case Report 1}

Our first patient was a 55-year-old male, who presented with a complaint of his right foot turning in and toes curling downward upon walking. The condition was initially only intermittent but later started to occur in all instances of forward walking. He had no abnormal posturing of the left lower extremity, upper extremities or any other body parts. He was an engineer by profession with no history of secondary causes of dystonia and the rest of the history including family history was unremarkable. Examination showed inward curling of all toes on his right foot induced by walking forward. His foot also appeared to plantar flex and invert with walking. The symptoms disappeared when he stopped walking as well as at rest. This abnormal posture was absent when walking backwards. There were no features of parkinsonism, and the rest of neurological examination was unremarkable. Nerve conduction studies, MRI of the brain and spine were normal, and serological investigations were normal. The targeted muscles for the botulinum toxin injection were the gastrocnemeus, soleus, tibialis posterior and the flexor digitorum. The patient showed significant improvement of symptoms following the botulinum toxin treatment at these specific muscles.

\section{Case Report 2}

The second case was a 56-year-old male who was a marathon runner. He reported experiencing an involuntary straightening of the left leg upon running which started 8 months ago. The straightening of the leg was accompanied by an upward and outward curling of the left foot. Within 5-7 min of starting a running motion, left leg started to get slow and straighten and his foot assumed an abnormal posture with dorsiflexion and eversion. The abnormal position of foot and leg disappeared once

\section{KARGER}

Fax +4161306 1234 E-Mail karger@karger.ch www.karger.com
(C) 2012 S. Karger AG, Base 0014-3022/13/0692-0065\$38.00/0

Accessible online at: www.karger.com/ene
Abdul Qayyum Rana

Parkinson's Clinic of Eastern Toronto and Movement Disorders Centre

404-2863 Ellesmere Rd.

Toronto, ON M1E5E9 (Canada)

E-Mail ranaaq@yahoo.com 
he stopped running. No disturbance in posture was observed while walking as well as running in the backward direction. There was also no abnormal posturing of his left leg at rest as well as upper extremities, right leg or any other body parts.

The inner side of his left running shoe was completely worn out as compared to the outer side. There were no secondary causes of dystonia; he was an administrative assistant, and his family history was also unremarkable. Nerve conduction studies, and EMG were normal as well as an MRI of the brain and spine.

\section{Discussion}

Dystonia is defined as a sustained muscle contraction causing frequent repetitive movement or an abnormal posture. Adult-onset task-specific dystonias are usually seen in upper limbs. Although rare, task-specific lower limb dystonia can occur in professionals such as dancers and runners $[1,6]$. Adult-onset dystonia of the lower limb involves distal limbs and results in abnormal, involuntary posturing such as inversion, eversion or plantar flexion of the foot [6]. This abnormal posturing of the foot in adults often can be traced back to identifiable causes such as Parkinson's disease or immune-mediated stiff limb syndrome [7]. Studies show that defective processing of sensory information in the sensory cortex may be involved in exercise-induced dystonia [8]. When the sole of the foot gets involved, the arch gets more pronounced, and this leads to plantar flexion of the toes in a passive manner which is perceived as curling. This was the abnormal foot posture seen in our first patient. This type of 'curling' resembles the posture of feet in a patient experiencing 'early morning foot dystonia [9]. Foot inversion is the more common posture seen in lower limb dystonias, whereas the foot eversion seen in our second patient is very rare [7]. Most reported cases of exerciseinduced foot dystonia involve the plantar flexion of foot and inward curling of the toes [10]. This is distinct from our second patient who experienced the dorsiflexion and eversion of his foot. This is an interesting case as studies show that this abnormal posture is relatively uncommon $[2,10]$.

In both cases, the symptoms have the tendency to evolve and may become more persistent with time. It is also possible that exercise-induced dystonia gradually loses its specificity to exercise and can start to occur during regular walking or standing [11]. The condition can escalate with environmental risk factors such as repetitive use or muscoskeletal constraints. It also seems to be aggravated with levodopa therapy in Parkinson's patients [3]. The preferred method of treatment involves the use of botulinum toxin as studies show that it improves symptoms especially when dystonia affects the foot $[4,6]$. The patient described in case report 1 showed improvement in symptoms after botuli- num toxin treatment. In his case, the injections targeted the gastrocnemeus, soleus, tibialis posterior and the flexor digitorum muscles. These muscles were determined to be involved in the plantar flexion and inversion of his foot as well as the inward curling of his toes. The patient described in case report 2 did not receive botulinum toxin treatment. The muscles involved in the abnormal dorsiflexion and eversion of his foot were determined to be tibialis interior and peronei; a botulinum toxin injection targeting these muscles could lead to a foot-drop during walking. This had to be avoided; therefore, the patient was not eligible for a botulinum toxin treatment. He was advised that his symptoms could be manageable if he were to run in shorter intervals or avoid running all together.

The differential symptoms between the two patients remain unexplained; however, we are aware of the possibility of a wide range of symptom expression. The neural mechanisms underlying specific cases of dystonia need to be assessed with care before starting treatment. The diversity in expression of dystonia highlights the diversity of the neural mechanisms that may be involved; therefore, it becomes important to treat only the neural pathways that are involved for each specific case of dystonia [4]. Further research can focus on the underlying links between particular muscle pathways that are affected and specific neuropathology to be able to explain the unique symptoms that patients express.

\section{References}

1 Pedro J, del Val J, Losada M: Task-specific dystonia of the lower limb in a flamenco dancer. Parkinsonism Relat Disord 2011;17: 221-222.

-2 Singer C, Papapetropoulos S: Adult onset primary focal foot dystonia. Parkinsonism Relat Disord 2006;12:57-60.

3 Lees AJ, Hardi RJ, Sterm GM: Kinesigenic foot dystonia as a presenting feature of Parkinson's disease. J Neurol Neurosurg Psychiatry 1984;47:885.

4 Giladi N, Meer J, Honigman S: The use of botulinum toxin to treat 'striatal' toes. J Neurol Neurosurg Psychiatry 1994;57:659.

5 Nygaard TG, Marsden CD, Fahn S: Doparesponsive dystonia: long-term treatment response and prognosis. Neurology 1992;41: 174-181.

6 Wu L, Jankovic J: Runner's dystonia. J Neurol Sci 2006;251:1-170.

7 McKeon A, Matsumoto JY, Bower JH, Ahlskog JE: The spectrum of disorders presenting as adult-onset focal lower extremity dystonia. Pakinsonism Relat Disord 2008;14: 613-619.
-8 Yoon JH, Lee PH, Yoon SN: Subtraction brain SPECT imaging in a patient with paroxysmal exercise-induced dystonia: role of primary somatosensory cortex. Arch Neurol 2007;64:1652-1656.

9 Poewe WH, Lees AJ, Stern GM: Dystonia in Parkinson's disease: clinical and pharmacological features. Ann Neurol 1988;23:73-78.

$\checkmark 10$ Bruno M, Ravina B, Garraux G, Hallett M, Ptacek L, et al: Exercise-induced dystonia as a preceding symptom of familial Parkinson's disease. Mov Disord 2004;19:228-230.

-11 Schneider S, Edwards MJ, Grill SE, Goldstein S, Kanchana S, et al: Adult-onset primary lower limb dystonia. Mov Disord 2006;21: 767-771. 